\title{
Editorial
}

\section{Food prices, inequity, and our responsibilities}

Mumbai. This editorial comes to you from India. I am reading the lead article in The Times of India. This expresses concern that the nation's growth rate is now at the rate of $8 \cdot 7 \%$, compared with $11 \cdot 2 \%$ last year. Imagine a newspaper in North America or Europe complaining about annual economic growth of nearly $9 \%$ !

On the same front page another headline states: 'Grain prices rising, set to soar further' with the subheading 'Widening gap means 854 million go hungry'. This is worried about the impact of the rapid rise in world food grain prices (wheat prices up by $92 \%$ between January and December 2007) is having on the number of hungry people in the world. It goes on to point out that annual North American food grain consumption is now $909 \mathrm{~kg}$ per person, compared with $179 \mathrm{~kg}$ per person in the Indian subcontinent and $552 \mathrm{~kg}$ in the European Union. The Times of India is also worried that India will need to import foods for the first time for many years, putting further pressure on world grain prices.

\section{It's not (just) cricket in India}

The third big issue in the news in India now is about the latest round of bidding for players to join the Indian premier cricket league - acknowledging that India is now the leading force in world cricket.

India's new national wealth is all too evident to a visitor. Trying to get around Mumbai is almost impossible now. Cars overwhelm the transport system; it can take several hours to travel just a few kilometres. All the new wealth in Mumbai adds to the congestion as more people buy cars. A new cheap people's car has just been launched, which will only make things worse. The papers are also now getting worried about the impact of rapid growth on the quality of life.

The urban economy is booming, and the Indian middle classes are doing very well. For the poorest and most vulnerable, it's a different story. According to the latest Millennium Development Goal report ${ }^{(1)}$, progress has been made towards achieving the 2015 goals but is far too slow. In India the percentage living on less than a dollar a day, the proportion who are hungry, and the maternal and infant mortality rates are all too high, and the gap between the rich and poor is growing.

\section{Kenya is not all smelling of roses}

A colleague from Kenya has been discussing with me the issue of exporting mange tout peas and cut flowers to the
UK, and the jobs these activities create for Kenyans - when the civil strife subsides - compared with the impact this has on the use of fossil fuels and carbon emissions. It seems that we in the rich North are asking the poorest in Kenya to pay the price for our consciences about global warming. We created the mess but the poorest have to suffer.

I hear similar stories in India. Middle-class people here are made to feel guilty about now being able to afford to fly around the world because of the impact this has on carbon emissions.

\section{The British rich get the gravy}

Writing the above also causes me to reflect on a recent report on childhood well-being in the twenty-one richest countries of the world ${ }^{(2)}$. Countries have been ranked using the six different dimensions of physical and mental well-being at personal, family and community level. The Netherlands came out top, the UK bottom, just below the USA. Over the last 10 years average life expectancy in the UK has risen, but the gap between the richest and poorest has widened. At the extremes, the gap is 20 years for bestand worst-off men ${ }^{(3)}$. The UK government has now admitted that it will not achieve the target it set itself for poverty reduction. The government has also recently had to revise its target for reducing obesity: since the target was set rates of obesity have actually gone up.

\section{What public health nutrition is all about}

What has the price of wheat, the availability of mange tout and the starving hundreds of millions got to do with public health nutrition? The answer is everything. Such economic, social and political issues are not beyond our scope. They are what public health is and always has been all about. Part of the vision of the New Nutrition Science project ${ }^{(4)}$ is that we all live in the same world. No man is an island - as John Donne wrote - and no woman and child, either. What happens in one place affects all of us. If the global environment and population well-being are to be nourished, sustained and hopefully improved, we need to engage with big picture issues.

World wheat prices are now so high partly because in many places the grain is grown to feed animals to be eaten as burgers. In India most people are still vegetarians or eat very little meat, but if they follow global trends they will increase their meat consumption and thus add to the demand for and waste of cereals. 
History is part of our remit also. We have to learn the lessons of the past, but not to burden those who have not been the cause of the problems with the solutions (at least primarily!). We have to identify realistic, fair, and equitable global solutions. This may involve those of us who have been lucky enough to be born in the rich North to pay more for food. We have to open access to our markets so that poorer producers living in the South can have a fair return for their work, and have more control over their own destiny. 'Trade not aid' is a good slogan for changing the North's relationship with the South.

The core content of this journal will always be original research papers. But we are not only about publishing evidence of public health problems and their causes. Like its subject, Public Health Nutrition is also committed to engage in and contribute to solutions. Public health will always have these social and political dimensions. Next month we will pursue this theme.

Barrie Margetts Deputy Editor

\section{References}

1. http://www.un.org/milleniumgoals/.

2. UNICEF (2007) An Overview of Child Well-being in Rich Countries. New York: UNICEF.

3. UK Department of Health (2008) Tackling Health Inequalities: 2007 Status Report on the Programme for Action. London: DoH.

4. Leitzmann C \& Cannon G (2005) The New Nutrition Science. Public Health Nutr 8, issue 6A, 667-804.

\section{In this issue}

\section{Do national research priorities align with burden of disease?}

Research has its greatest utility when it can be applied to address individual, societal, population and ecological problems. If you agree with this statement, then it is not unreasonable to assume that you would agree with Llanos et al.'s ${ }^{(1)}$ proposition in this issue that the alignment of research priorities with the corresponding population burden of disease is desirable, to enhance the effectiveness and efficiency of actions required to improve health. This paper contrasts the epidemiological profile of nine Latin American countries with the research priorities in academic institutions in each country and finds a misalignment between public health nutrition needs and research priorities. Their finding that studies on the efficacy and effectiveness of interventions were uncommon reinforces the ongoing challenge for public health nutrition researchers and practitioners to prioritise and provide this evidence through intervention research.

Haerens et $a l^{(2)}$ have responded to this challenge in their paper explaining the effect of a 1-year intervention promoting physical activity in middle schools, using mediation analysis.

\section{Food diversity and neophobia affects dietary quality}

Diversity in food consumption is widely recognised as an important predictor of dietary quality, particularly among indigenous peoples. In this issue, Roche et al. $^{(3)}$ assess the utility of a food diversity score for predicting nutrient adequacy among the Awajún culture of the Peruvian Amazon. At the other end of the diversity spectrum, Schickenberg et al. ${ }^{(4)}$ explore the effect of food neophobia on acquaintance with and willingness to try healthful foods among Dutch consumers. It appears that lower educational attainment and opportunity is associated with greater neophobia in the context of healthful foods.

\section{Yet another argument for breast-feeding promotion}

Noor and Rousham ${ }^{(5)}$ present results from a cross-sectional household survey of infant feeding and maternal well-being among women in north-east England of Bangladeshi and Pakistani ethnicity. Their data suggest an important mediating role of breast-feeding in maternal mental health after childbirth, providing yet another good reason for promoting breastfeeding as the norm and proactively supporting this feeding choice among mothers.

Roger Hughes Deputy Editor

\section{References}

1. Llanos A, Oyarsun MT, Bonvecchio A, Rivera J \& Uauy R (2002) Are research priorities in Latin America in line with 